\title{
Quantitative Microscopic Approaches for Studying Kidney Functions
}

\author{
Weiming $\mathrm{Yu}$ \\ Department of Medicine, Indiana University School of Medicine, Nephrology Division, Indianapolis, Ind., USA
}

\author{
Key Words \\ Glomerular permeability · Tubular reabsorption • \\ Charge selectivity · Two-photon excitation • \\ Multiphoton
}

\begin{abstract}
Intravital ratiometric microscopy is a powerful method for quantitative study of kidney functions. As demonstrated in the examples, both the generalized polarity and direct ratio imaging approaches allow investigators to address basic and important questions such as those related to filtration, permeability and reabsorption. Both approaches have similar advantageous for in vivo imaging. However, they have different sensitivities and responses to the component intensity changes. Therefore, investigators must design their experiments based on the characteristics of the generalized polarity function and direct ratio approach.
\end{abstract}

Copyright (C) 2006 S. Karger AG, Basel

\section{Introduction}

Normal functions of the kidney are directly associated with filtration, reabsorption and excretion for the regulation of salt and water content of the body, removing waste products and maintaining chemical balance of the blood. Intravital two-photon fluorescence microscopy holds particular promise to study these processes as it allows observations of local regions of the kidney, such as the glo- merulus, proximal tubule and distal tubule cells, with subcellular and submicron resolutions, and at the same time with nanomolar concentration sensitivity [1]. Due to the comprehensive parameters we are able to evaluate with intravital microscopy, quantitative approaches become increasingly important in studying kidney function and associated disease processes. For fluorescence application, it is typically difficult to directly use the intensity values for quantification due to the temporal and spatial fluctuations caused by the imaging system, the sample and the imaging environment. For in vivo imaging, local intensity values can be further affected by the physiological processes such as blood flow, heart beat, breathing and animal movement. A relatively simple way for quantitative image analysis is to use intensity ratios. Here we summarize recent advances and new developments in applying ratiometric-imaging techniques for kidney studies.

\section{Ratiometric Methods for Image Quantification}

By infusing a bulk solution of selected fluorescent dyes into the animal, one can monitor fluorescence changes of the dyes over time to evaluate filtration, transport processes of these molecules in the renal tubules, and microvascular permeability within the kidney [2]. Quantitative evaluation of these processes is essential to interpret these experiments. Recently, a quantitative approach using a generalized polarity (GP) concept was implemented to analyze the multidimensional data obtained from multidextran infusion experiments [3].

\section{KARGER}

(ㄱ) 2006 S. Karger AG, Basel

Fax +41613061234

E-Mail karger@karger.ch

www.karger.com
Accessible online at: www.karger.com/nep
Dr. Weiming $\mathrm{Yu}$

Department of Medicine, Indiana University School of Medicine

Nephrology Division, $950 \mathrm{~W}$. Walnut Street, R2-268

Indianapolis, IN 46202 (USA)

Tel. +1 317278 4481, Fax +1 317274 8575, E-Mail wmyu@iupui.edu 


\section{Generalized Polarity Method}

The GP function compares the relative intensities of two fluorescent dyes and has the same form as the polarization function [4]:

$$
G P_{A / B}=\frac{I_{A(\text { large })}-I_{B(\text { small })}}{I_{A(\text { large })}+I_{B(\text { small })}}
$$

where $I_{A(\text { large })}$ and $I_{B(\text { small })}$ are the fluorescence intensity emitted from molecule A (measured in channel A) and B (measured in channel B), respectively. When two fluorescent dextrans are used, the pixel value of GP images represents the relative molecular distributions of the dextrans within local regions of the kidney at given time intervals after infusion. By definition, GP has a minimum value of -1 (small molecules only) and a maximum value of +1 (large molecules only). Equal distributions of the fluorescence intensity given by the two molecules results in a $\mathrm{GP}=0$ (no polarity). In other words, polarity refers to differential spatial occupation of the two molecules. For a GP image an individual pixel value (on the GP scale) represents the relative molecular ratio of the two molecules. In real application one needs to consider the fact that the fluorescent dye molecules used for animal infusion may not have equal fluorescence. To take into account this initial polarity offset, $\mathrm{GP}_{(\mathrm{A} / \mathrm{B}) 0}$, in practice, one needs to use the differential GP defined as:

$$
\Delta G P_{A / B}=G P_{A / B}-G P_{(A / B) 0}
$$

This value is more useful because what we are interested in knowing is the changes made by the kidneys, but not so much the absolute GP values.

\section{$\Delta$ GP Image: A Map of Relative Molecular Concentration Changes}

By infusing multiple fluorescent molecules into the animal, one can obtain a wealth of information about kidney functions using intravital microscopy, e.g. how different molecules are being filtered or retained within the kidney vasculature [3, 5-7]; the dynamic processes of endocytosis of molecules in the proximal tubules [1, 8, 9]; how diseases can affect kidney function in processing these molecules $[6,10]$. For quantification purpose, in many cases, what we try to analyze are the concentrations of different molecules. The GP image is essentially a map showing relative molecular concentrations of the fluorescent molecules, while the $\Delta \mathrm{GP}$ image is a map of concentration changes of the molecules with respect to those of the original infused dye mixture. $\Delta \mathrm{GP}$ image facilitates direct observation and comparison of relative molecular concentration changes at different locations of the kid- ney. Figure $1 \mathrm{~A}$ is a $\Delta \mathrm{GP}$ image of $70-$ and $40-\mathrm{kDa}$ dextrans at $4 \mathrm{~s}$ after infusion. The relative concentration changes of the two molecules can be seen from the pseudocolor scale of the image. Examples of regional $\Delta \mathrm{GP}$ distribution are shown in figure $1 \mathrm{~A}^{\prime}$. At this time point (4 $\mathrm{s}$ after infusion), the concentration ratio between the 70- and $40-\mathrm{kDa}$ dextrans should be very close to that of the dextran mixture being infused. As a result, the $\Delta \mathrm{GP}_{70 \mathrm{kDa} / 40 \mathrm{kDa}}$ distribution of the blood plasma was only slightly shifted above zero (fig. $1 \mathrm{~A}^{\prime}$, trace 3 ). This positive shift indicates an increase of the $70-\mathrm{kDa} / 40-\mathrm{kDa}$ molecular ratio. To the contrary, as the $40-\mathrm{kDa}$ dextran was filtered through the glomerular barrier more efficiently than the $70-\mathrm{kDa}$ dextran did, the concentration increase of the $40-\mathrm{kDa}$ dextran surpassed that of the $70-\mathrm{kDa}$ dextran. As a result, the $\Delta \mathrm{GP}_{70 \mathrm{kDa} / 40 \mathrm{kDa}}$ distributions from Bowman's space and the proximal tubule lumen shifted towards negative values (fig. 1 $\mathrm{A}^{\prime}$, traces 1 and 2 ). Figure $1 \mathrm{~B}$ is another example of $\Delta \mathrm{GP}$ image taken at $36 \mathrm{~min}$ after dextran infusion. At this time point, the $\Delta \mathrm{GP}_{70 \mathrm{kDa} / 40 \mathrm{kDa}}$ distribution from within the blood vessels (fig. $1 \mathrm{~B}^{\prime}$, trace 6 ) was further shifted away from zero and towards the $100 \%$ concentration level of the $70-\mathrm{kDa}$ dextran (red dotted and dashed line in fig. $1 \mathrm{~A}^{\prime}$ and $\mathrm{B}^{\prime}$ ). As the $40-\mathrm{kDa}$ dextran was accumulated from a $36-\mathrm{min}$ time period in the distal tubules, their $\Delta \mathrm{GP}_{70 \mathrm{kDa} / 40 \mathrm{kDa}}$ distributions (fig. 1 $1 \mathrm{~B}^{\prime}$, traces 4 and 5) became negatively shifted towards the $100 \%$ concentration level of the 40-kDa dextran.

By performing GP imaging, one can quantitatively analyze many dynamic processes of the kidney [3]. In the following, we focus on the use of GP analysis to quantify glomerular filtration and proximal tubular charge selectivity in molecular reabsorption.

\section{Glomerular Permeability}

For multi-dextran infusion experiments there are at least two ways to evaluate glomerular permeability using $\Delta \mathrm{GP}$ analysis. One way is to monitor $\Delta \mathrm{GP}$ changes in the bloodstream as a function of time after infusion. Typically, smaller size molecules are filtered and cleared faster than larger molecules from the blood and vice versa. Therefore, the relative concentration changes over time in the blood, of two molecules with different sizes, are effective measures of glomerular filtration function. For example, the $\Delta \mathrm{GP}_{70 \mathrm{kDa} / 40 \mathrm{kDa}}$ values of blood plasma steadily increased with time (fig. 2). This is understandable as the $40-\mathrm{kDa}$ dextran was cleared faster than the $70-\mathrm{kDa}$ dextran and the concentration fraction of the $70-\mathrm{kDa}$ dextran in the blood thus increased. In figure 2, the upper 
A

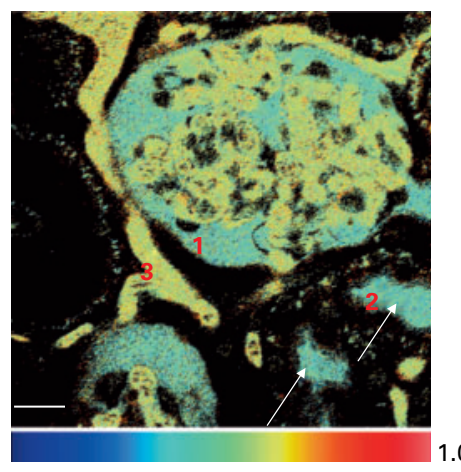

$-1.2$ 1.0

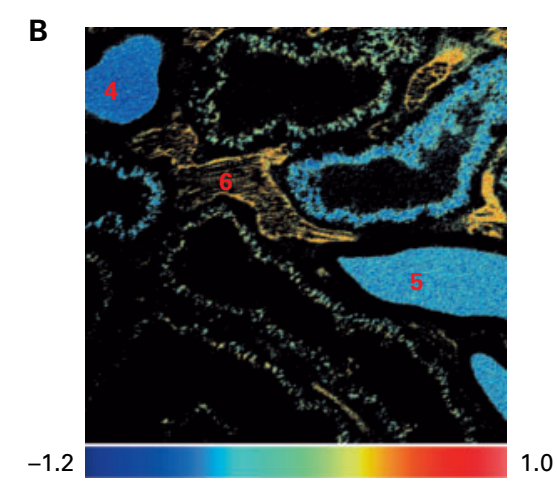

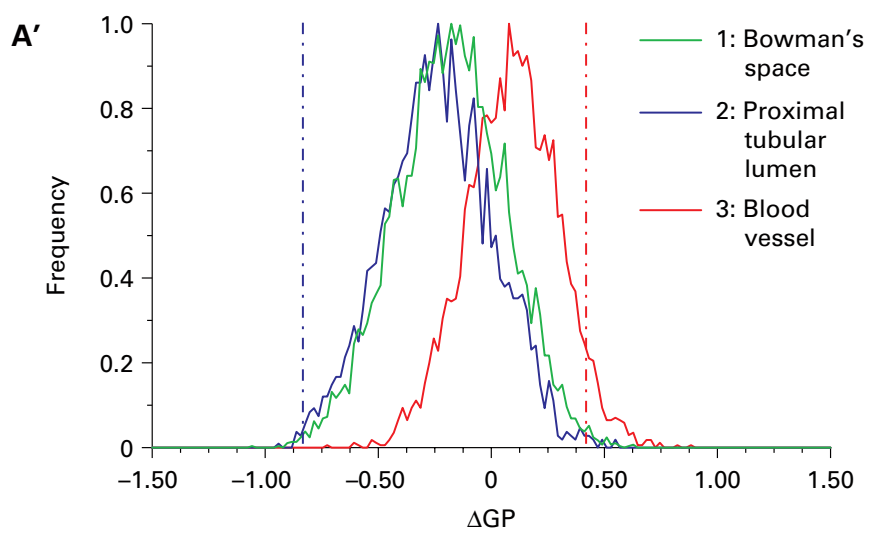

$\mathbf{B}^{\prime}$

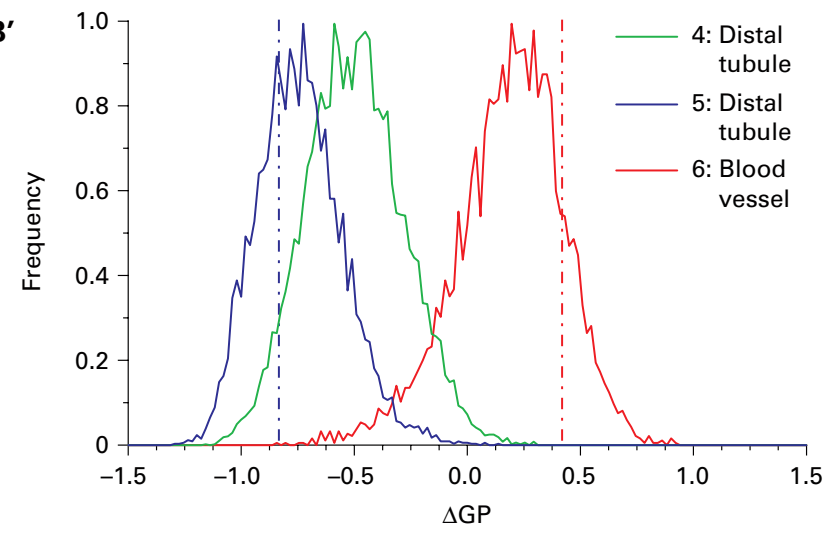

Fig. 1. $\Delta \mathrm{GP}$ images and local $\Delta \mathrm{GP}$ distributions of the kidney from a Munich-Wistar Frömter (MWF) rat at $4 \mathrm{~s}(\mathbf{A})$ and $36 \mathrm{~min}$ (B) after dextran infusion intravenously. Intravital imaging of the kidney and image analysis was performed using the procedures described earlier [3]. A mixture of fluorescently labeled dextrans containing the 70-kDa FITC-dextran (anionic), the 40-kDa tetramethylrhodamine dextran (neutral) and the $3-\mathrm{kDa}$ cascade-blue dextran (data not shown) were infused into an 8-week-old MWF rat. A, B $\Delta \mathrm{GP}_{70 \mathrm{kDa} / 40 \mathrm{kDa}}$ images in pseudocolor. Regions of in- terest ( $\mathrm{ROI}>3,000$ pixels) analyses were performed on the indicated areas (1: Bowman's space; 2: proximal tubular lumen; 3: blood vessel lumen; 4 and 5: distal tubules; 6: blood vessel lumen). $\mathbf{A}^{\prime}, \mathbf{B}^{\prime} \Delta \mathrm{GP}_{70 \mathrm{kDa} / 40 \mathrm{kDa}}$ distributions of ROI for areas 1-6 indicated in $\mathbf{A}$ and $\mathbf{B}$. The blue and red dot and dashed lines represent the average $\Delta \mathrm{GP}_{70 \mathrm{kDa} / 40 \mathrm{kDa}}$ values of the $40-$ and $70-\mathrm{kDa}$ dextrans alone, respectively. All $\Delta$ GP values are displayed in pseudocolor with a range as indicated. Scale bar in $\mathbf{A}, 20 \mu \mathrm{m}$. range of the y-axis we used $\Delta \mathrm{GP}_{70 \mathrm{kDa} / 40 \mathrm{kDa}}=0.413$. This is the $\Delta \mathrm{GP}_{70 \mathrm{kDa} / 40 \mathrm{kDa}}$ value of the $100 \% 70-\mathrm{kDa}$ dextran when measured under our experimental conditions using equations 1 and 2 . In this case, the concentration of molecule B was zero. The intensity signal $\mathrm{I}_{\mathrm{B}(\text { small) }}$ was the fluorescence signal originating from molecule $\mathrm{A}$ (the 70-kDa dextran) measured in channel B due to cross-talk. By comparing the $\Delta \mathrm{GP}_{70 \mathrm{kDa} / 40 \mathrm{kDa}}$ values measured at different time points with one of the 100\% 70-kDa dextrans, one can get a sense of the dynamics of relative clear- ance between the 70- and 40-kDa dextrans. When 70- and 3-kDa dextrans were used for $\Delta \mathrm{GP}$ analysis, the blood $\Delta \mathrm{GP}_{70 \mathrm{kDa} / 3 \mathrm{kDa}}$ values were quickly approaching the respective $\Delta \mathrm{GP}$ value of the $100 \% 70-\mathrm{kDa}$ dextran. If we use cascade-blue-labeled 3-kDa dextran, the fluorescence signal from the 3-kDa dextran dropped to the background level at around $100 \mathrm{~s}$ after infusion.

The other way to evaluate glomerular filtration is to measure $\Delta$ GP values within Bowman's space using different pairs of dextrans at a given time after infusion. If 
Fig. 2. $\Delta \mathrm{GP}$ changes in the bloodstream with time increases after infusion. Errors were determined using the $\Delta \mathrm{GP}_{70 \mathrm{kDa} / 40 \mathrm{kDa}}$ values of three regions of blood vessels from a given $\Delta \mathrm{GP}$ image. The upper range of the $\Delta \mathrm{GP}$ axis has a value of $\Delta \mathrm{GP}_{70 \mathrm{kDa} / 40 \mathrm{kDa}}=$ 0.413 and corresponds to the $100 \%$ level of the $70-\mathrm{kDa}$ dextran. As seen from the bar graph, the $40-\mathrm{kDa}$ dextran was being filtered already at $7.3 \mathrm{~s}$. However, relative concentration changes between the 70 - and 40-kDa dextrans with time increases were gradual. At 36 min there was still a significant portion of the $40-\mathrm{kDa}$ dextran in the blood.

Fig. 3. Differential filtration of dextrans with different sizes. A $\Delta$ GP of different dextran pairs in the Bowman's space at $4 \mathrm{~s}$ after infusion. Errors were determined using the $\Delta \mathrm{GP}$ values of three regions of the Bowman's space from a corresponding image. B Instantaneous sieving coefficient, $\theta(\mathrm{t})$ of the 70-, 40- and 3-kDa dextrans calculated using the same intensity images for $\Delta \mathrm{GP}$ analysis obtained at $4 \mathrm{~s}$ after infusion. Inset, color combined image showing the $70-\mathrm{kDa}$ dextran (green), the 40-kDa dextran (red) and the $3-\mathrm{kDa}$ dextran (blue). Large errors of $\theta(\mathrm{t})$ were from large intensity differences from different blood vessel regions (e.g. areas 1-3). The intensity values from within Bowman's space (indicated with white arrows, shown in purple) were relatively uniform.
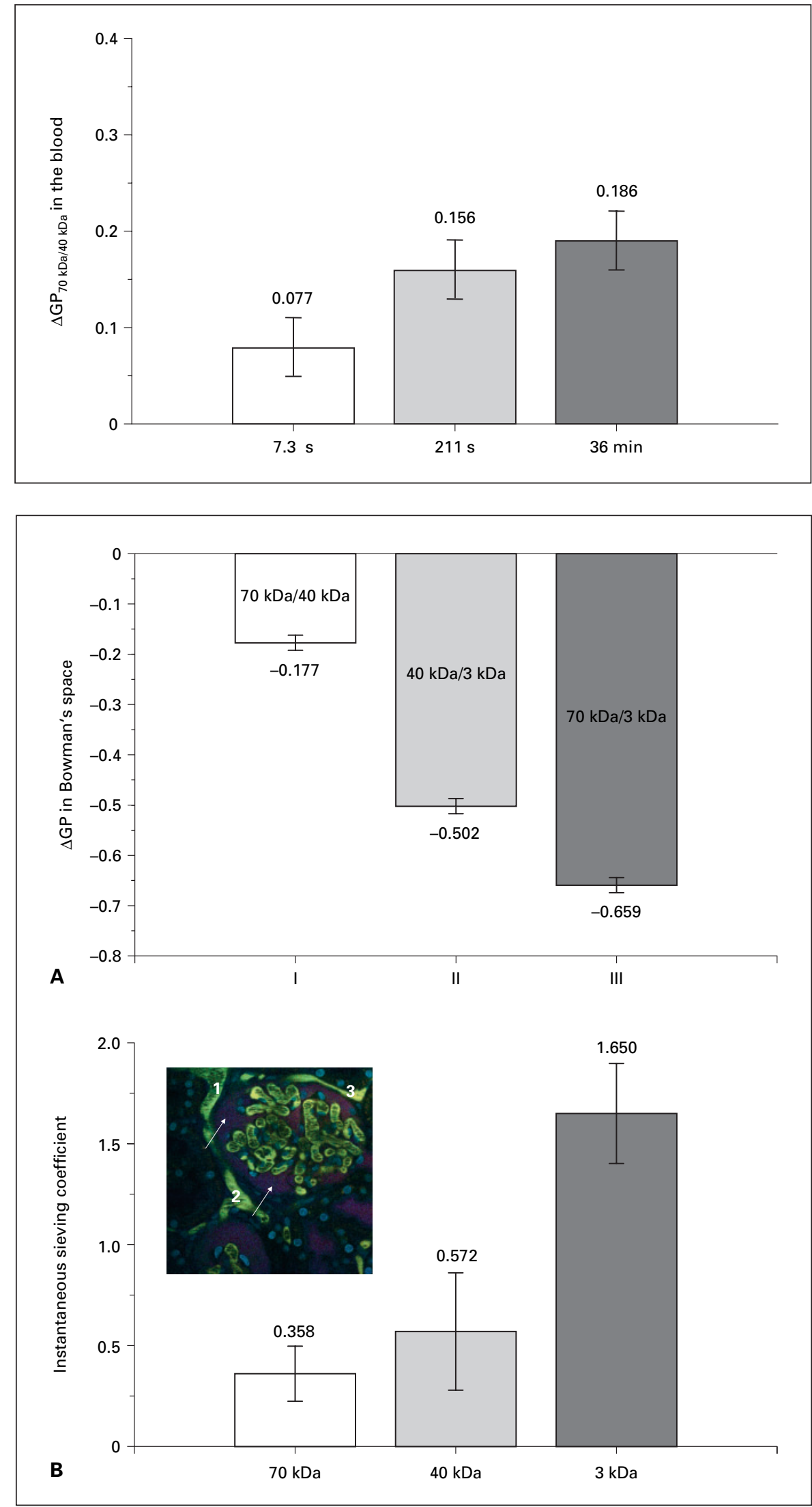
we take a snapshot of a glomerulus a few seconds after infusion of multiple dextrans, the concentration ratios among different dextrans in the blood should be very close to those from the mixture just being injected. In other words, the $\Delta \mathrm{GP}$ values of different dextran pairs in the bloodstream should not have large shifts away from zero. However, in Bowman's space the $\Delta$ GP values should be negatively shifted since molecules with smaller size will appear faster than larger molecules. In other words, at any given time the concentration of a smaller molecule is higher than that of a larger molecule in Bowman's space. For example, in figure 3 we plot $\Delta \mathrm{GP}$ values of three dextran pairs from a multi-dextran infusion experiment. As expected, the relative concentrations of the dextrans in Bowman's space have the following sequence [3 kDa] $>[40 \mathrm{kDa}]>[70 \mathrm{kDa}]$. Consequently, in figure $3 \mathrm{~A}, \Delta \mathrm{GP}_{70 \mathrm{kDa} / 3 \mathrm{kDa}}$ has the largest negative shift. Because the different $\Delta \mathrm{GP}$ values were obtained at the same time, effectively, the degrees of the negative $\Delta \mathrm{GP}$ shifts indicate the relative permeability of the glomerulus to different size dextrans. Please note that this measurement was done on an 8-week-old Munich-Wistar-Frömter (MWF) rat that had spontaneous albuminuria [11, 12] and its glomeruli were leaky to large-size molecules. One could also calculate the instantaneous sieving coefficients, $\theta(t)$ (defined in equation 3), of the dextrans to evaluate glomerular permeability,

$$
\theta(t)=I_{\text {Bowman's Space }}(t) / I_{\text {Blood }}(t)
$$

where $I_{\text {Bowman's Space }}(t)$ and $I_{\text {Blood }}(t)$ are, respectively, fluorescence intensities of any one of the dextrans from areas of a Bowman's space and areas from within the blood vessels of an intensity image at a time shortly after infusion. As a comparison, we plot $\theta(t)$ of the 70-, 40- and $3-\mathrm{kDa}$ dextran at $4 \mathrm{~s}$ after infusion (fig. 3B) using the same data set for obtaining figure $3 \mathrm{~A}$. This plot also indicates glomerular permeability was the highest for the $3-\mathrm{kDa}$ dextran and lowest for the 70-kDa dextran. However, the errors using instantaneous sieving coefficient were significantly larger than those using $\Delta \mathrm{GP}$ (fig. $3 \mathrm{~A}$ ). This was largely due to intensity fluctuations from the blood caused by variations of blood flow speed within different vessels (fig. 3B, inset, large spatial intensity variations from within different blood vessels). In addition, errors due to nonuniformity of fluorescence intensity across the image propagate to the calculated $\theta(t)$. Both of these errors are suppressed using $\Delta \mathrm{GP}$ analysis. As a result, one can continuously monitor subtle changes of glomerular permeability using $\Delta \mathrm{GP}$ approach.

\section{Charge Effect of Proximal Tubular Reabsorption}

Whether there is glomerular permselectivity of charged molecules remains a controversial question $[7,13,14]$. This controversy is in part due to the lack of direct in vivo experimental methods that can clearly separate and resolve glomerular filtration from renal tubular reabsorption and enzymatic processing. In fact, we need to answer two separated questions: 1 . Does the glomerular filtration barrier filter molecules with different charges differently? 2. Do renal tubules reabsorb molecules with different charges differently? Quantitative $\Delta \mathrm{GP}$ analysis can provide answers to these questions. By performing GP imaging with a healthy Sprague-Dawley rat using 40-kDa neutral and $40-\mathrm{kDa}$ negatively charged dextrans [3], it was

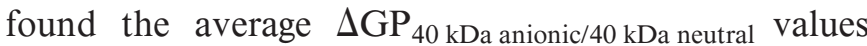
from within the blood vessels stayed around zero from a few seconds to more than $240 \mathrm{~s}$ after infusion (fig. 4D, inset). This result implies the concentration ratio between the two $40-\mathrm{kDa}$ dextrans in the blood were the same as in the preinfusion mixture. This ratio maintained as a constant over time. Clearly, both 40-kDa dextrans were filtered through the glomerular barrier, as shown in figure 4A and B (white arrows), where both dextrans were visualized in the proximal tubule lumens after infusion. These results suggest that both the negatively charged and neutral dextrans were filtered equally by kidney glomeruli.

To evaluate the reabsorptive properties of the proximal tubules, one can analyze the $\Delta$ GP values from a number of different aspects: (1) by directly focusing on the epithelial cells of the proximal tubules; (2) by focusing on the proximal tubule lumens at a given time; (3) by comparing the $\Delta \mathrm{GP}$ values from within the proximal tubule lumens at different time points after infusion, and (4) by comparing the $\Delta \mathrm{GP}$ values from the proximal tubule lumens with those from within Bowman's space. For example, at $66 \mathrm{~s}$ after infusion of the $40-\mathrm{kDa}$ neutral and negative charged dextrans, the average

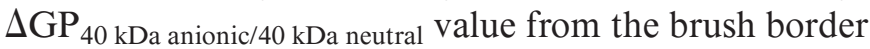
of the proximal tubular cells was positively shifted (fig. $4 \mathrm{D}, \mathrm{C}$, areas indicated with white arrows, shown in red). This suggests there was an accumulation of the negatively charged dextran by the proximal tubule cells. To the contrary, in the proximal tubular lumen, the average $\Delta \mathrm{GP}_{40 \mathrm{kDa}}$ anionic/40 kDa neutral value was negatively shifted (fig. 4D, C, lumen areas shown in green) suggesting an accumulation of the $40-\mathrm{kDa}$ neutral dextran. Since both 40-kDa negative and neutral charge dextrans were filtered equally $\left(\Delta \mathrm{GP}_{40} \mathrm{kDa}\right.$ anionic/40 $\mathrm{kDa}$ neutral $=0$ from within the blood vessels), these results clearly indicate that mole- 

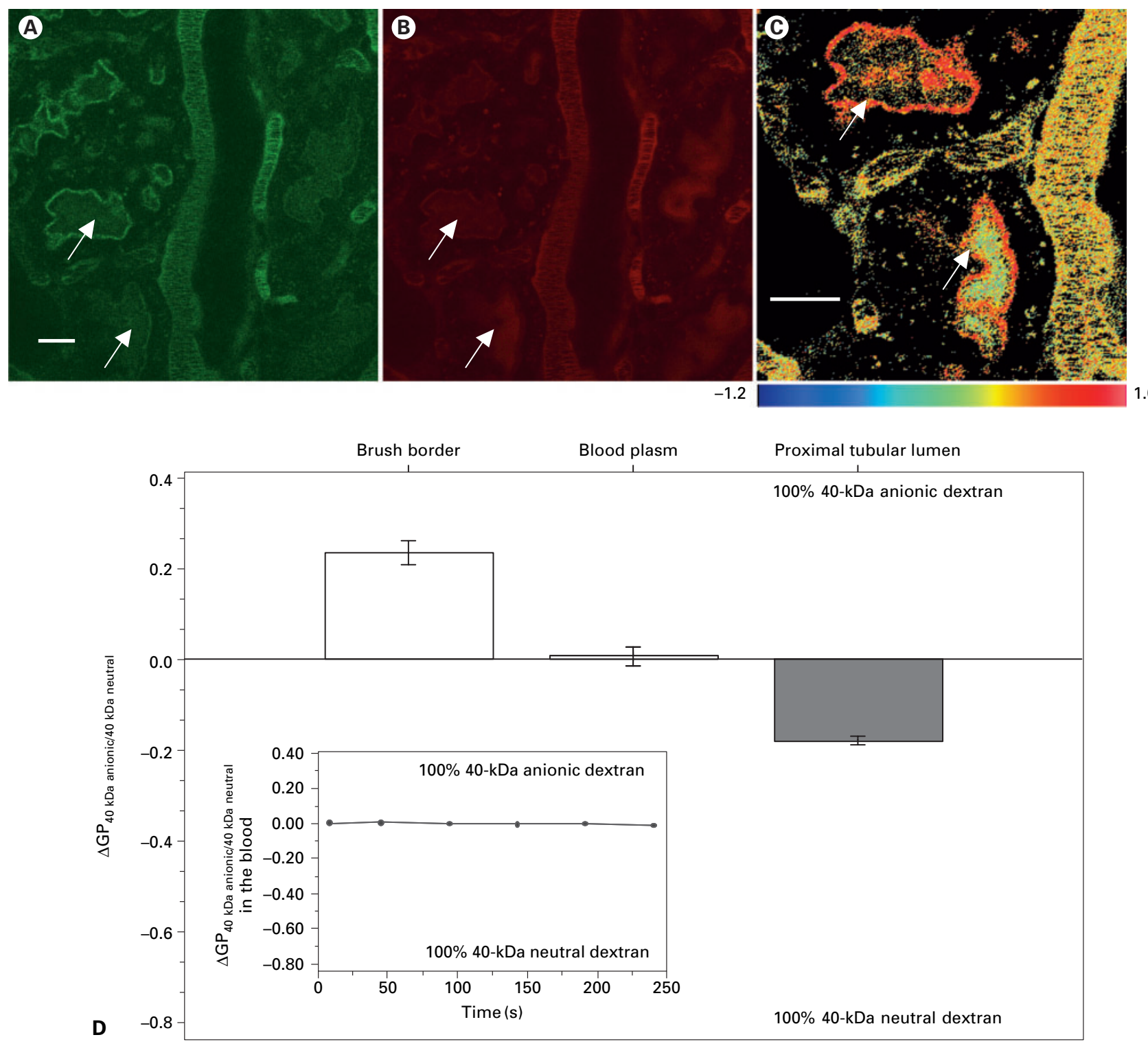

Fig. 4. Charge selectivity in glomerular filtration and proximal tubular reabsorption. Intravital kidney images were taken using an 8-week-old Sprague-Dawley rat after intravenous infusion of a dextran mixture containing equal concentrations of the 40-kDa FITCdextran (anionic) and the 40-kDa tetramethylrhodamine dextran (neutral). A, B Intensity images of the 40-kDa FITC-dextran and 40-kDa tetramethylrhodamine dextran, respectively, at $\sim 30 \mathrm{~s}$ after infusion. Both dextrans were present in the proximal tubule lumens (white arrows in both $\mathbf{A}$ and $\mathbf{B}$ ). C $\Delta \mathrm{GP}_{40 \mathrm{kDa} \text { anionic/40 kDa neutral }}$ image in pseudocolor at $66 \mathrm{~s}$ after dextran infusion. The brush borders of proximal epithelial cells show relative high accumula- tions of the negatively charged $40-\mathrm{kDa}$ dextran (indicated with white arrows). The proximal tubule lumen (in green) shows relative high accumulations of the neutral $40-\mathrm{kDa}$ dextran.

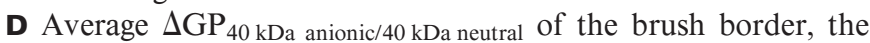
blood plasma and the proximal tubular lumen. D Inset, $\Delta \mathrm{GP}_{40} \mathrm{kDa}$ anionic/40 $\mathrm{kDa}$ neutral from within the blood vessel stayed at around zero as a function of time after dextran infusion. The ranges of the $\Delta \mathrm{GP}$ axis in $\mathbf{D}$ are from $-0.84(100 \%$ neutral dextran) to 0.413 (100\% negatively charged dextran). Scale bars in $\mathbf{A}$ and C, $20 \mu \mathrm{m}$. 
Fig. 5. Using intensity ratio for clearance rate measurements. Intravital images of the kidney were taken as a function of time after intravenous infusion of a mixture containing $3 \mathrm{kDa}$ FITC-inulin and 500 TexasRed dextran to a Sprague-Dawley rat. The intensity ratio values of $\mathrm{I}_{\text {inulin }} / \mathrm{I}_{500} \mathrm{kDa}$ dextran from a blood vessel region are plotted (square) as a function of time. Least square fit (solid line) to a single exponential decay yielded a rate constant, $\mathrm{k}=0.0079 \mathrm{~s}^{-1}$. Inulin clearance rate can be calculated as $k V$ where $V$ is the total inulin distribution volume.

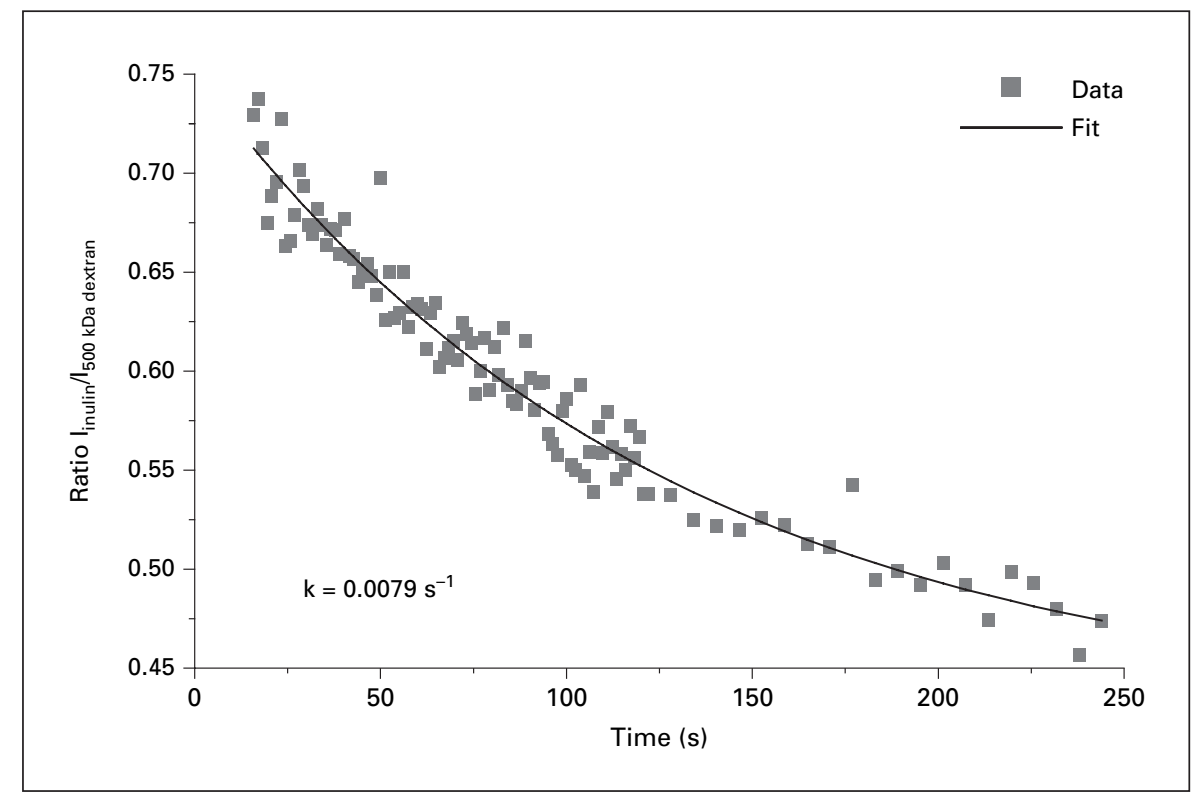

cules with the same molecular weight, but different charges, were reabsorbed to different extents by proximal tubule cells. Additional evidence can be found from figure $1 \mathrm{~A}$ where both the Bowman's space and proximal tubules

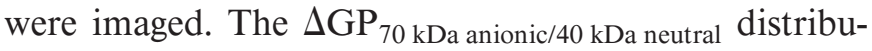
tion from within proximal tubule lumens (with an average $\Delta \mathrm{GP}_{70 \mathrm{kDa} \text { anionic } / 40 \mathrm{kDa} \text { neutral }}=-0.193$ ) was more negatively shifted than the distribution from within the Bowman's space (with an average $\Delta \mathrm{GP}_{70} \mathrm{kDa}$ anionic/40 kDa neutral $=-0.177$ ). This result suggests there was a loss of the negatively charged $70-\mathrm{kDa}$ dextran from glomerular filtrate when it moved from Bowman's space into the proximal tubule lumens.

\section{Direct Ratio Method to Quantify Renal Clearance \\ Rates}

Directly using intensity ratio is a simple and useful method for image quantification. Traditionally, quantitative analysis using ratio imaging requires working together with ratiometric probes that typically change their spectroscopic properties with environmental changes. Direct ratioing methods have been employed broadly in studying ion dynamics in cells. This classical ratio imaging technique has been extended to use multiple fluorescent dyes to study relative protein concentration changes in cells $[15,16]$. Similarly, one can monitor relative concentration changes of the dextrans using the direct ratio $\left(\mathrm{R}=\mathrm{I}_{\mathrm{A}} / \mathrm{I}_{\mathrm{B}}\right)$, in the multi-dextran infusion experiments. As an example, in figure 5 we plot the intensity ratio to mon-

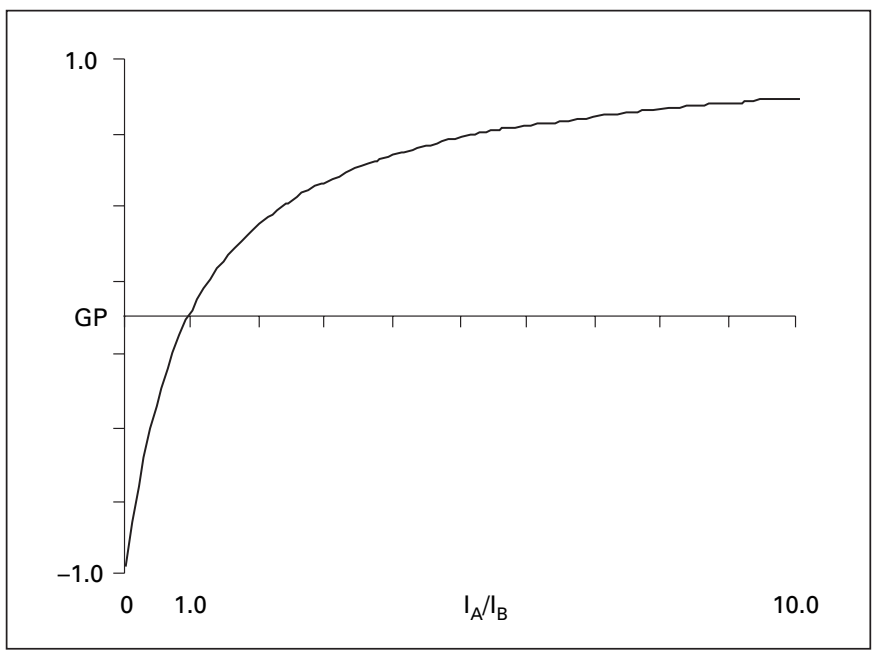

Fig. 6. Relationship between GP and intensity ratio. GP is sensitive intensity ratio changes when $\mathrm{I}_{\mathrm{A}}<\mathrm{I}_{\mathrm{B}}$ or when $\mathrm{I}_{\mathrm{A}} \approx \mathrm{I}_{\mathrm{B}}$. GP is relatively insensitive (gradually reach a plateau) when $I_{A} \gg I_{B}$.

itor concentration changes between FITC-inulin and 500-kDa Texas-Red-conjugated dextran from within the blood vessels after infusion. As a reasonable assumption, the $500-\mathrm{kDa}$ dextran is not filtered by the kidneys. Effectively, the ratio profile in figure 5 is a measure of inulin clearance from the blood. One can retrieve a rate constant of $0.0079\left(\mathrm{~s}^{-1}\right)$ for inulin clearance by performing least square fit to a single exponential. 
One could also use direct ratioing, instead of GP (equation 1), for the image analysis mentioned above. In fact, every ratio value can be converted to a corresponding GP value and vice versa. The differences between using direct ratio and GP are: (1) GP value is normalized between -1 and +1 and convenient for comparison; (2) there is a linear response in the direct ratio following a change in $\mathrm{I}_{\mathrm{A}}$ or $\mathrm{I}_{\mathrm{B}}$. The response in GP, however, is not linear (fig. 6). Instead, as seen in figure 6, steep changes in GP occur when $\mathrm{I}_{\mathrm{A}} / \mathrm{I}_{\mathrm{B}} \leq 1$. In other words, it is advantageous to detect subtle changes with GP when the intensity from molecule A is lower or at about the same level as that from molecule B.

\section{Advantages of Using Ratiometric Imaging}

Similar to other ratiometric-imaging techniques, both GP and direct ratio methods are sensitive to relative concentration changes of the two fluorescent probes. This is advantageous for studying processes involving extensive and rapid concentration changes such as those related to glomerular filtration and tubular reabsorption processes. Ratiometric-imaging methods are relatively independent of the amount of fluorescent probes injected, the excitation power and the depth of field being imaged. These characteristics are particularly helpful for quantitative imaging of live animals where the amount of dyes used, the appropriate levels of laser power used, and imaging depth all vary with individual animals. In addition, using ratiometric techniques, spatial variations of the fluorescence signals across the field of view due to detector/sample non-uniformity are also minimized.

Intravital microscopy is a relatively new and enabling technique for studying kidneys. It facilitates our investigation by offering a direct view of the microstructure of the kidney. As demonstrated in the above examples, quantitative imaging techniques further enable us to better understand the data related to kidney functions. The kidney is an extremely complex system. The parameters we demand to know are many, from fluid flow rates in renal tubules to molecular reabsorption rates to cellular ion concentrations, just name a few. To understand the biological complexities of the kidney, it is essential that one applies all possible means at hand. Quantitative imaging techniques can play key roles in advancing our understanding of these processes.

\section{Acknowledgements}

This work was supported by a startup fund from an Indiana Genomics Initiative (INGEN) grant from the Eli Lilly endowment to Indiana University School of Medicine and a pilot study from a NIH O'Brien Center of Excellence Grant (P50 DK61594).

\section{References}

1 Dunn KW, Sandoval RM, Kelly KJ, Dagher PC, Tanner GA, Atkinson SJ, Bacallao RL, Molitoris BA: Functional studies of the kidney of living animals using multicolor two-photon microscopy. Am J Physiol 2002;283:C905C916.

-2 Sutton TA, Fisher CJ, Molitoris BA: Microvascular endothelial injury and dysfunction during ischemic acute renal failure. Kidney Int 2002;62:1539-1549.

- 3 Yu W, Sandoval RM, Molitoris BA: Quantitative intravital microscopy using a generalized polarity concept for kidney studies. Am J Physiol 2005;289:C1197-C1208.

4 Yu WM, So PTC, French T, Gratton E: Fluorescence generalized polarization of cell membranes: a two-photon scanning microscopy approach. Biophys J 1996;70:626-636.

-5 Molitoris BA, Sandoval RM: Intravital multiphoton microscopy of dynamic renal processes. Am J Physiol Renal Physiol 2005;288: F1084-F1089.
6 Sutton TA, Kelly KJ, Mang HE, Plotkin Z, Sandoval RM, Dagher PC: Minocycline reduces renal microvascular leakage in a rat model of ischemic renal injury. Am J Physiol Renal Physiol 2005;288:F91-F97.

-7 Schaeffer RC Jr, Gratrix ML, Mucha DR, Carbajal JM: The rat glomerular filtration barrier does not show negative charge selectivity. Microcirculation 2002;9:329-342.

8 Sandoval RM, Kennedy MD, Low PS, Molitoris BA: Uptake and trafficking of fluorescent conjugates of folic acid in intact kidney determined using intravital two-photon microscopy. Am J Physiol 2004;287:C517-C526.

-9 Dunn KW, Sandoval RM, Molitoris BA: Intravital imaging of the kidney using multiparameter multiphoton microscopy. Nephron Exp Nephrol 2003;94:e7-e11.

10 Sutton TA, Mang HE, Campos SB, Sandoval RM, Yoder MC, Molitoris BA: Injury of the renal microvascular endothelium alters barrier function after ischemia. Am J Physiol Renal Physiol 2003;285:F191-F198.

-11 Schulz A, Standke D, Kovacevic L, Mostler M, Kossmehl P, Stoll M, Kreutz R: A major gene locus links early onset albuminuria with renal interstitial fibrosis in the MWF rat with polygenetic albuminuria. J Am Soc Nephrol 2003; 14:3081-3089.

12 Schulz A, Litfin A, Kossmehl P, Kreutz R: Genetic dissection of increased urinary albumin excretion in the Munich-Wistar-Frömter rat. J Am Soc Nephrol 2002;13:2706-2714.

13 Guimaraes MA, Nikolovski J, Pratt LM, Greive K, Comper WD: Anomalous fractional clearance of negatively charged Ficoll relative to uncharged Ficoll. Am J Physiol Renal Physiol 2003;285:F1118-F1124.

14 Rippe B: What is the role of albumin in proteinuric glomerulopathies? Nephrol Dial Transplant 2004;19:1-5.

15 Kam Z, Zamir E, Geiger B: Probing molecular processes in live cells by quantitative multidimensional microscopy. Trends Cell Biol 2001; 11:329-334.

-16 Zamir E, Katz BZ, Aota S, Yamada KM, Geiger B, Kam Z: Molecular diversity of cell-matrix adhesions. J Cell Sci 1999;112:16551669. 